\begin{tabular}{c|c|c}
\hline \hline $\begin{array}{c}\text { Vol. 36(1):59-69 } \\
\text { http://dx.doi.org/10.4217/OPR.2014.36.1.059 }\end{array}$ & Ocean and Polar Research & March 2014 \\
\hline
\end{tabular}

Article

\title{
Characteristics of Semi-diurnal and Diurnal Currents at a KOGA Station over the East China Sea Shelf
}

\author{
Su-Yun Noh ${ }^{1}$, Young Ho Seung ${ }^{*}$, Eun-Pyo Lim ${ }^{1}$, and Hak-Yeol You ${ }^{2}$ \\ ${ }^{1}$ Department of Oceanography, College of Natural Sciences, Inha University \\ Incheon 402-751, Korea \\ ${ }^{2}$ Oceanographic Division, Korea Hydrographic and Oceanographic Administration \\ Busan 606-806, Korea
}

\begin{abstract}
The long-term mooring performed at a KOGA station, located at about $30^{\circ} 20^{\prime} \mathrm{N}, 126^{\circ} 12^{\prime} \mathrm{E}$ in the East China Sea shelf, shows some different behaviors between "semi-diurnal" and "diurnal currents" defined as the currents with periods around, respectively, a half day and a day. They appear to be predominantly tidal having significant coherences with sea level changes around the semi-diurnal and diurnal frequencies. The "semi-diurnal current" is strongly barotropic all year round. However, contrastingly, it is largely baroclinic in summer in the area about $70 \mathrm{~km}$ nearer to the continental slope, referred to as the "slope-area", as was found in previous current observations. The "diurnal current" of tidal origin is strongly barotropic in winter. In spring and summer, however, it becomes more baroclinic although it still remains largely barotropic, also showing more of its barotropic nature than in the "slope-area". The inertial oscillation contributing to the "diurnal current" appears to be more prominent when the current is baroclinic, indicating the important role played by stratification in generation of inertial oscillations. Downward energy propagation of inertial oscillation is not observed, suggesting that it is not created at the surface by wind. Considering that the study area is both near a critical latitude and proximity to the continental slope, it is suggested that parametric subharmonic instability (PSI) plays a significant role in creating the baroclinic inertial oscillation.
\end{abstract}

Key words : semi-diurnal current, diurnal current, East China Sea, KOGA

\section{Introduction}

The East China Sea (ECS) is a marginal sea located in the northwestern part of the Pacific Ocean (Fig. 1). For the most part it is comprised of a shallow continental shelf area which is distinguished from the oceanic area by a continental slope running in a southwest - northeast direction. The shelf region is greatly affected by the Kuroshio, the western boundary current of the North Pacific, flowing along the continental slope. The Kuroshio is known to leak onto the shelf taking two different courses; one through the Taiwan Strait (further to the southwest, not shown in Fig. 1) called the Taiwan Warm Current and the

\footnotetext{
*Corresponding author. E-mail : seung@inha.ac.kr
}

other through the northeastern end of the slope west of Kyushu (Lie and Cho 1994; Ichikawa and Beardsley 2002; Isobe 2008). They join each other to form the Tsushima Current. The latter ultimately flows into the East/Japan Sea either passing by the western coast of Jeju Island or directly to the Korea Strait (Lie et al. 2001). This feature of oceanic current is, however, very variable and the detailed passage of the current is not exactly known, especially near the central region of the East China Sea shelf where the branches of the Tsushima Current seem to join each other (Takahashi and Morimoto 2013).

Over the shelf area of the ECS, semi-diurnal and diurnal tides predominate with the former stronger than the latter (Choi 1980; Yanagi et al. 1997, Larsen et al. 1985). Energetic internal tides are known to be generated near 


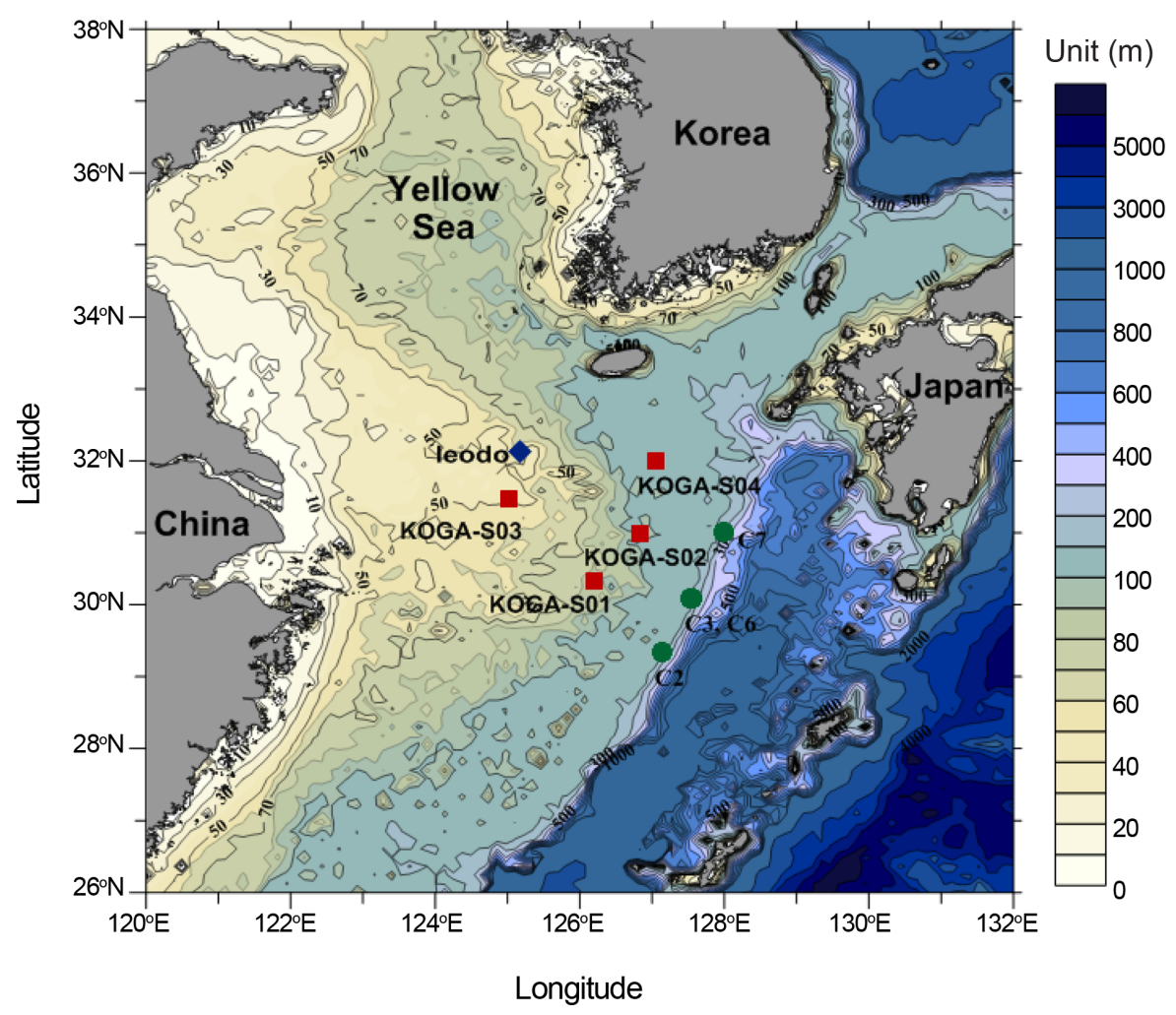

Fig. 1. Topographic map with positions of Ieodo station (blue diamond), and the mooring points in the "KOGA-area" (red squares) and the "slope-area" (green circles)

the continental slope (Baines 1982; Niwa and Hibiya 2004; Kuroda and Mitsudera 1995). Park et al. (2011) have observed semi-diurnal internal tides and near-inertial internal waves in the area near the continental slope in the summer season, although the latter waves might also be interpreted as diurnal internal tides because the inertial period in that area (about 23.76 hours) is so close to the period of $\mathrm{K}_{1}$ diurnal tidal constituent (23.93 hour) that differentiating between the two is very hard (refer to Fig. 1 for the latitude of the study area). Moreover, this area, referred hereafter to as the "slope-area", can be considered to be very close to the critical latitude for the reason described below. At the critical latitude, where the local inertial period becomes twice that of a major tidal constituent, energy is transferred resonantly from the tidal wave to the inertial wave through non-linear wave-wave interaction called the parametric subharmonic instability (briefly PSI) described by MacKinnon et al. (2013). Hence, the energy transfer from $\mathrm{S}_{2}$ tidal wave to near-inertial wave through the PSI is possible in this area. For PSI to occur in the "slope-area", vertically low-mode internal waves of $\mathrm{S}_{2}$ tidal constituent should be present, which is quite probable considering the topographic nature of this area.
However, there is not yet any supporting observation to confirm this.

Considering the fact that long-term oceanographic measurements over the shelf of the ECS have been scanty, the Korea Hydrographic and Oceanographic Administration (KHOA) launched a long-term mooring project, called the Korea Ocean Gate (KOGA), near the onshore side of the "slope-area" where the branch currents join each other to form the Tsushima Current (Fig. 1). The area covered by the KOGA project, in which moorings named KOGA have been established (Fig. 1), is referred to as the "KOGAarea" in differentiation from the "slope-area". The aim of KOGA is to clarify the long-term variation of oceanic currents in this region, as well as that of higher-frequency motions. This paper focuses on the latter part of the aim, that is, on understanding the characteristics of currents with semi-diurnal and diurnal periods in the "KOGAarea" and their seasonal variation. The results are then compared with those obtained previously in the nearby "slope-area". For later convenience, the current with semidiurnal periods, referred to as the "semi-diurnal current", is defined as a mixture of motions with periods around a half day, mostly tidal currents. In the same way, the current 
with diurnal periods, referred to as the "diurnal current", is defined as a mixture of those motions with periods around a day, mostly tidal currents and inertial oscillation created either by wind or by non-linear interaction such as the PSI.

\section{Data and Methods}

Among the many KOGA mooring points, we consider only the point KOGA-SO1 which gives the longest term and most reliable data. It is located at about $70 \mathrm{~km}$ onshore

Table 1. Summary of the observations in the "KOGA-area"

\begin{tabular}{cccccc}
\hline Station & Latitude & Longitude & Period & Bottom depth & Time interval \\
\hline KOGA-S01 & $30^{\circ} 19^{\prime} 47.34^{\prime \prime}$ & $126^{\circ} 12^{\prime} 11.56^{\prime \prime}$ & $2011.08-2012.05$ & $81 \mathrm{~m}$ & $30 \mathrm{~min}$ \\
KOGA-S02 & $30^{\circ} 59^{\prime} 15.43^{\prime \prime}$ & $126^{\circ} 49^{\prime} 38.77^{\prime \prime}$ & $2011.08-2012.02$ & $96 \mathrm{~m}$ & $30 \mathrm{~min}$ \\
KOGA-S03 & $31^{\circ} 27^{\prime} 47.55^{\prime \prime}$ & $125^{\circ} 01^{\prime} 52.81^{\prime \prime}$ & $2011.08-2011.09$ & $47 \mathrm{~m}$ & $10 \mathrm{~min}$ \\
KOGA-S04 & $30^{\circ} 00^{\prime} 10.84^{\prime \prime}$ & $127^{\circ} 02^{\prime} 43.48^{\prime \prime}$ & $2011.08-2011.11$ & $115 \mathrm{~m}$ & $30 \mathrm{~min}$ \\
\hline
\end{tabular}
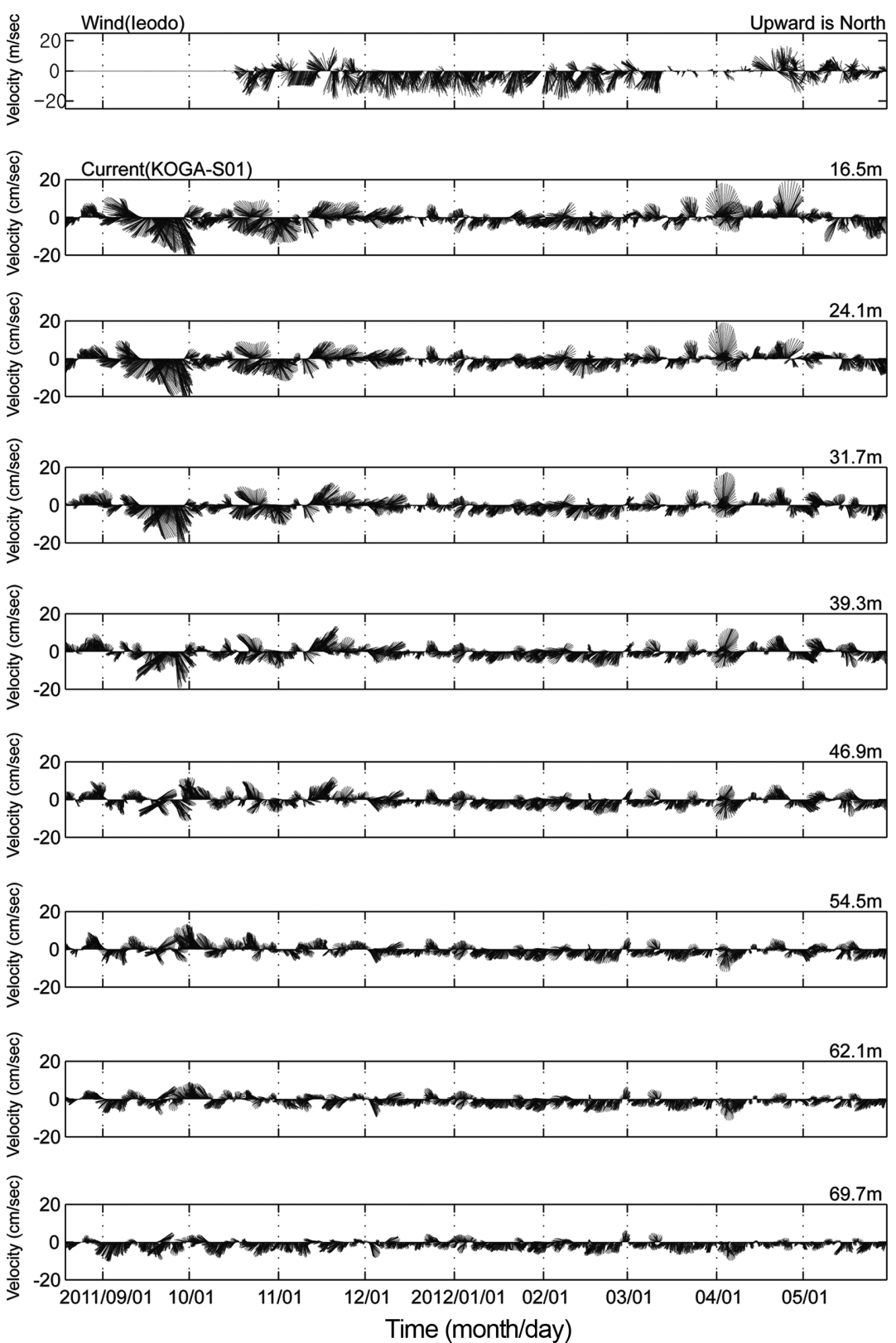

Fig. 2. Time series of the observed wind and current at each depth 

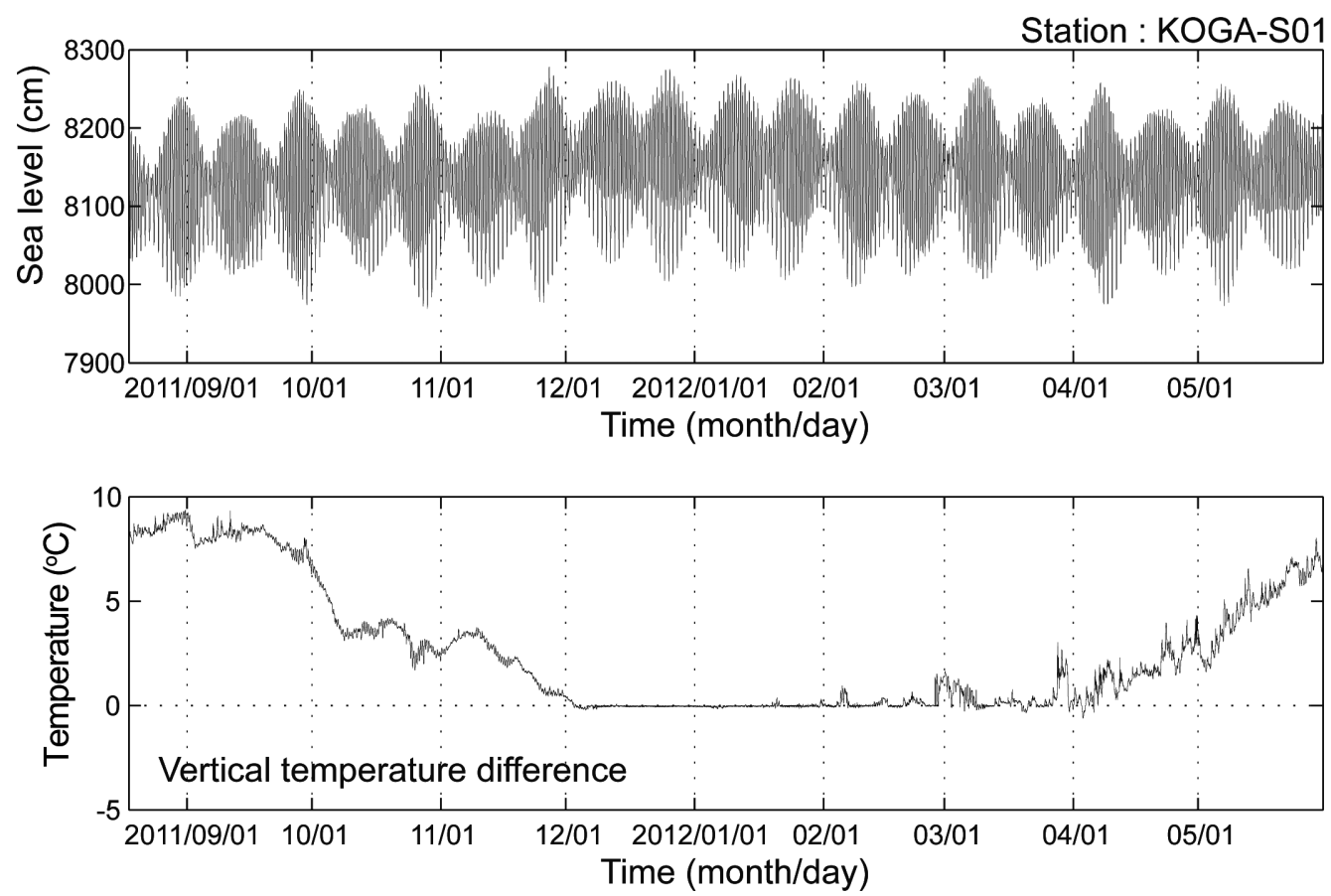

Fig. 3. Time series of observed surface elevation and vertical temperature difference

of the "slope-area" that is occupied by moorings $\mathrm{C} 2$ through C7 (Fig. 1). At this mooring point, an ADCP current meter measured the vertical profiles of the current. Two temperature sensors measured the surface and bottom temperatures, and a pressure gage measured the bottom pressure that can be converted to surface elevation. The sea surface elevation is not adjusted to the atmospheric pressure because it is dominated by a tidal effect. The meteorological instruments on the observation tower located at the Ieodo station measured wind at the same time (Fig. 1). These observations are summarized in Table 1, the time series of wind measured at Ieodo station and currents observed at point KOGA-SO1 are shown in Fig. 2, and observations of the surface elevation and vertical temperature difference measured at the same point are shown in Fig. 3. For more details about the KOGA project and the Ieodo station, refer to, respectively, KHOA (2012) and IEODO Ocean Research Station, http://ieodo.khoa.go.kr (KHOA 2013).

Spectral and rotary spectral analyses were performed according to the method described by Emery and Thomson (1997) using the Fast Fourier Transform method. To look more deeply into the time variation of spectral behavior, wavelet analyses were performed following the method proposed by Torrence and Compo (1998). Tidal constituents are obtained by doing tidal harmonic analysis following the method proposed by Pawlowicz et al. (2002). In conducting the wavelet and harmonic analyses, computations are performed using the codes provided by the MATLAB. In addition, the Butterworth band-pass filter with frequency band 1/24.8-1/22.8 cycles per hour (cph) was used in estimating the time series of inertial oscillation, as will be shown later. This filter extracts about $95.6 \%$ of periodic oscillation at the inertial frequency, i.e., $\mathrm{H}\left(\omega_{\mathrm{f}}\right)=0.956$ at $\omega=\omega_{\mathrm{f}}$ where $\mathrm{H}$ is frequency response function, $\omega$ is frequency and $\omega_{\mathrm{f}}=1 / 23.76 \mathrm{cph}$ is inertial frequency. For reference, $\mathrm{H}\left(\omega_{\mathrm{k}}\right)=0.953$ where $\omega_{\mathrm{k}}=1 / 23.93 \mathrm{cph}$ is the frequency of $\mathrm{K}_{1}$ tidal constituent which, practically, is removed before the band-pass filter is applied. Note that $\mathrm{H}\left(\omega_{\mathrm{f}}\right)$ increases with the band width. However, noises coming from the nearby frequencies also increase with the band width. Hence, the value of the band width used above is determined experimentally considering these facts.

\section{Results}

During the observation period, from Aug., 2011 to May, 2012, currents were highly variable with a general southwestward direction and the prevailing wind was notably southward in winter (Fig. 2). Cross-spectral analyses did not show any significant coherence between the wind at Ieodo station and current at almost all frequencies considered (not shown). The same analyses that were performed with the ECMWF wind gave the same result. 
Sea level changes show a mixture of semi-diurnal, diurnal and fortnightly variations, indicating the predominance of tidal influences (Fig. 3). Vertical temperature differences confirm the strongest and weakest stratifications in, respectively, summer and winter (Fig. 3). Tidal harmonic constituents are extracted by harmonic analyses from nearly ten months-long sea level data (Table 2). Spectral analyses show that they form spectral peaks notably around semidiurnal and diurnal periods. They are mostly $\mathrm{M}_{2}, \mathrm{~S}_{2}, \mathrm{~N}_{2}$ and $\mathrm{K}_{2}$ tidal constituents for semi-diurnal periods, and $\mathrm{K}_{1}$, $\mathrm{O}_{1}$ and $\mathrm{P}_{1}$ tidal constituents for diurnal periods (Fig. 4). The almost ten months-long current data were also put into the tidal harmonic analyses exactly in the same way as that for sea level change (Table 3). Rotary spectral analyses show similar energy peaks around the same semi-

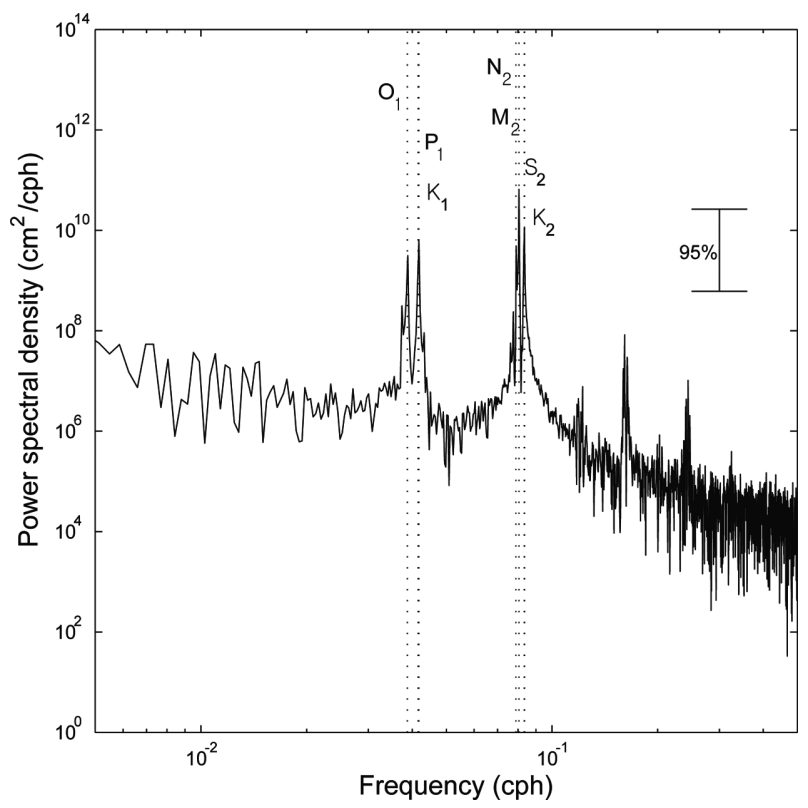

Fig. 4. Power spectral densities of sea level change. Frequencies of major tidal constituents, $\mathrm{O}_{1}, \mathrm{P}_{1}, \mathrm{~K}_{1}$, $\mathrm{N}_{2}, \mathrm{M}_{2}, \mathrm{~S}_{2}$ and $\mathrm{K}_{2}$, are indicated

Table 2. Results of tidal harmonic analyses of sea level changes. Only the major constituents are presented

\begin{tabular}{cccc}
\hline Constituent & $\begin{array}{c}\text { Period } \\
\text { (hour) }\end{array}$ & $\begin{array}{c}\text { Amplitude } \\
\text { (cm) }\end{array}$ & $\begin{array}{c}\text { Phase } \\
\text { ( ) }\end{array}$ \\
\hline $\mathrm{K}_{2}$ & 11.97 & 8.10 & 99.42 \\
$\mathrm{~S}_{2}$ & 12.00 & 30.28 & 105.96 \\
$\mathrm{M}_{2}$ & 12.42 & 67.09 & 85.16 \\
$\mathrm{~N}_{2}$ & 12.66 & 13.34 & 84.79 \\
$\mathrm{~K}_{1}$ & 23.93 & 22.86 & 303.40 \\
$\mathrm{P}_{1}$ & 24.07 & 7.41 & 303.69 \\
$\mathrm{O}_{1}$ & 25.82 & 16.48 & 292.74 \\
\hline
\end{tabular}

diurnal and diurnal tidal periods, with the clockwise-rotating component stronger than the anti-clockwise component (Fig. 5). The inertial oscillation may also contribute to these peaks although it has a period (23.76 hours) so close to the period of the $\mathrm{K}_{1}$ tidal constituent (23.93 hours) that distinguishing between them is difficult in terms of spectral analyses. The predominance of tidal forcing in current behavior can be evidenced by the good coherences between current and sea level change around the semi-diurnal and diurnal frequencies (Fig. 6). In order to see the time evolution of vertical structure, wavelet spectra of kinetic energy were calculated by averaging the two wavelet spectra obtained for eastward and northward components of the current (Fig. 7). The current at the semi-diurnal periods, the "semi-diurnal current", is nearly independent of depth and can be compared well with the pattern of sea level change (Fig. 3). It seems to be predominantly barotropic without any notable seasonal variation. However, the current at the diurnal periods, the "diurnal current", has a more complicated vertical structure with significant seasonal variation.

To look more closely into the differences in behavior between the "semi-diurnal" and "diurnal currents", two time series for the whole observation period were constructed using the major tidal constituents: one using the semidiurnal constituents, $\mathrm{M}_{2}, \mathrm{~S}_{2}, \mathrm{~N}_{2}$ and $\mathrm{K}_{2}$ and the other using the diurnal constituents, $\mathrm{K}_{1}, \mathrm{O}_{1}$ and $\mathrm{P}_{1}$. The former series can be considered to represent the "semi-diurnal current" and the latter the "diurnal current" of tidal origin. The "diurnal current" of non-tidal origin should come from the inertial oscillation. The time series of inertial oscillation is estimated as follows. First, the time series of tidal current for the whole observation period is obtained by combining all available harmonic constituents including the minor constituents not shown in Table 3. The time series of detided current is then calculated by subtracting the tidal current, obtained above, from the raw data. Finally, the time series of inertial oscillation is estimated by applying the Butterworth band-pass filter, described in the previous section, to the de-tided current. Barotropic and baroclinic kinetic energies contained in the "semi-diurnal current", the "diurnal current" of tidal origin and the estimated inertial oscillation are calculated as follows.

$$
\begin{aligned}
& E_{t}=\frac{1}{2}<\bar{u}^{2}+\bar{v}^{2}> \\
& E_{c}=\frac{1}{2}<\bar{u}^{\prime 2}+\bar{v}^{\prime 2}>
\end{aligned}
$$

where $E_{t}$ and $E_{c}$ are, respectively, the barotropic and 
Table 3. Results of tidal harmonic analyses of currents at each depth. Only the major constituents are presented

\begin{tabular}{|c|c|c|c|c|c|c|c|c|}
\hline Depth & Constituents & $\mathbf{K}_{2}$ & $\mathbf{S}_{2}$ & $\mathbf{M}_{2}$ & $\mathbf{N}_{2}$ & $\mathbf{K}_{1}$ & $\mathbf{P}_{1}$ & $\mathbf{O}_{1}$ \\
\hline \multirow[t]{4}{*}{$16.5 \mathrm{~m}$} & Maj. & 3.18 & 13.85 & 31.61 & 6.42 & 7.61 & 1.47 & 5.76 \\
\hline & Min. & 1.37 & 8.74 & 22.52 & 4.66 & 6.61 & 1.09 & 5.39 \\
\hline & Inc. & 161.47 & 155.57 & 156.07 & 143.74 & 60.53 & 52.25 & 64.92 \\
\hline & Pha. & 245.68 & 252.07 & 230.55 & 233.18 & 162.69 & 171.81 & 161.81 \\
\hline \multirow[t]{4}{*}{$24.1 \mathrm{~m}$} & Maj. & 2.92 & 13.93 & 31.59 & 6.36 & 6.50 & 0.66 & 6.17 \\
\hline & Min. & 1.33 & 8.83 & 22.50 & 4.61 & 6.21 & 0.49 & 5.81 \\
\hline & Inc. & 163.23 & 156.95 & 155.81 & 141.77 & 58.80 & 82.10 & 78.15 \\
\hline & Pha. & 246.26 & 250.47 & 230.76 & 233.77 & 162.13 & 201.69 & 150.02 \\
\hline \multirow[t]{4}{*}{$31.7 \mathrm{~m}$} & Maj. & 2.61 & 13.89 & 31.52 & 6.29 & 6.12 & 0.24 & 5.82 \\
\hline & Min. & 1.33 & 8.96 & 22.39 & 4.56 & 5.77 & 0.08 & 5.33 \\
\hline & Inc. & 165.05 & 156.61 & 155.85 & 143.88 & 46.28 & 149.89 & 74.84 \\
\hline & Pha. & 244.52 & 250.10 & 230.61 & 232.53 & 167.41 & 79.10 & 153.34 \\
\hline \multirow[t]{4}{*}{$39.3 \mathrm{~m}$} & Maj. & 2.53 & 13.98 & 31.51 & 6.24 & 5.13 & 0.77 & 4.99 \\
\hline & Min. & 1.27 & 9.09 & 22.42 & 4.56 & 4.83 & 0.59 & 4.54 \\
\hline & Inc. & 169.56 & 156.86 & 155.29 & 146.92 & 24.44 & 4.84 & 67.04 \\
\hline & Pha. & 243.94 & 249.03 & 230.34 & 229.67 & 181.04 & 210.19 & 160.45 \\
\hline \multirow[t]{4}{*}{$46.9 \mathrm{~m}$} & Maj. & 2.61 & 14.08 & 31.53 & 6.33 & 3.59 & 2.04 & 4.50 \\
\hline & Min. & 1.31 & 9.16 & 22.33 & 4.61 & 3.23 & 1.89 & 4.30 \\
\hline & Inc. & 169.45 & 156.43 & 155.16 & 146.66 & 15.02 & 28.79 & 67.98 \\
\hline & Pha. & 247.16 & 247.60 & 229.18 & 228.86 & 196.72 & 167.72 & 156.85 \\
\hline \multirow[t]{4}{*}{$54.5 \mathrm{~m}$} & Maj. & 2.89 & 14.12 & 31.52 & 6.34 & 2.97 & 2.31 & 4.06 \\
\hline & Min. & 1.57 & 9.06 & 22.29 & 4.66 & 2.53 & 2.27 & 3.74 \\
\hline & Inc. & 168.70 & 154.51 & 154.72 & 145.77 & 10.80 & 25.39 & 73.44 \\
\hline & Pha. & 243.79 & 245.27 & 227.41 & 227.94 & 214.72 & 143.92 & 156.03 \\
\hline \multirow[t]{4}{*}{$62.1 \mathrm{~m}$} & Maj. & 3.19 & 13.49 & 30.72 & 6.00 & 2.71 & 1.96 & 2.99 \\
\hline & Min. & 1.71 & 8.51 & 21.63 & 4.46 & 2.17 & 1.85 & 2.76 \\
\hline & Inc. & 166.68 & 153.67 & 153.73 & 143.98 & 11.36 & 144.41 & 62.62 \\
\hline & Pha. & 234.10 & 241.41 & 224.55 & 226.16 & 218.01 & 23.48 & 174.78 \\
\hline \multirow[t]{4}{*}{$69.7 \mathrm{~m}$} & Maj. & 3.05 & 12.11 & 27.99 & 5.45 & 2.41 & 1.64 & 2.16 \\
\hline & Min. & 1.54 & 7.32 & 19.40 & 3.99 & 1.94 & 1.32 & 2.10 \\
\hline & Inc. & 162.03 & 153.98 & 152.90 & 145.50 & 4.81 & 155.08 & 589.89 \\
\hline & Pha. & 224.14 & 238.81 & 221.19 & 222.44 & 222.57 & 27.16 & 179.05 \\
\hline
\end{tabular}

Maj. : major axis of tidal ellipse $(\mathrm{cm} / \mathrm{sec})$

Min. : minor axis of tidal ellipse $(\mathrm{cm} / \mathrm{sec})$

Inc. : inclination of major axis (counter-clockwise from east) $\left(^{\circ}\right)$

Pha. : phase $\left({ }^{\circ}\right)$

baroclinic kinetic energies, $u$ and $v$ are eastward and northward components of the current, the over-bar denotes vertical average, the prime denotes deviation from the vertical average, and the $<>$ denotes time-average. Considering that the "diurnal current" appears to be highly dependent on season, this calculation is done for three different sub-periods: from Aug., 2011 to Sep., 2011 representing summer, from Dec., 2011 to Feb., 2012 representing winter, and from Apr., 2012 to May, 2012 representing spring. It appears that the "semi-diurnal current" is dominantly barotropic in all seasons (Table 4). The "diurnal current" of tidal origin is strongly barotropic in winter as it is for the "semi-diurnal current". However, it becomes more baroclinic in spring and summer when stratification is stronger than in winter, although it still remains largely barotropic. Interestingly, the inertial 

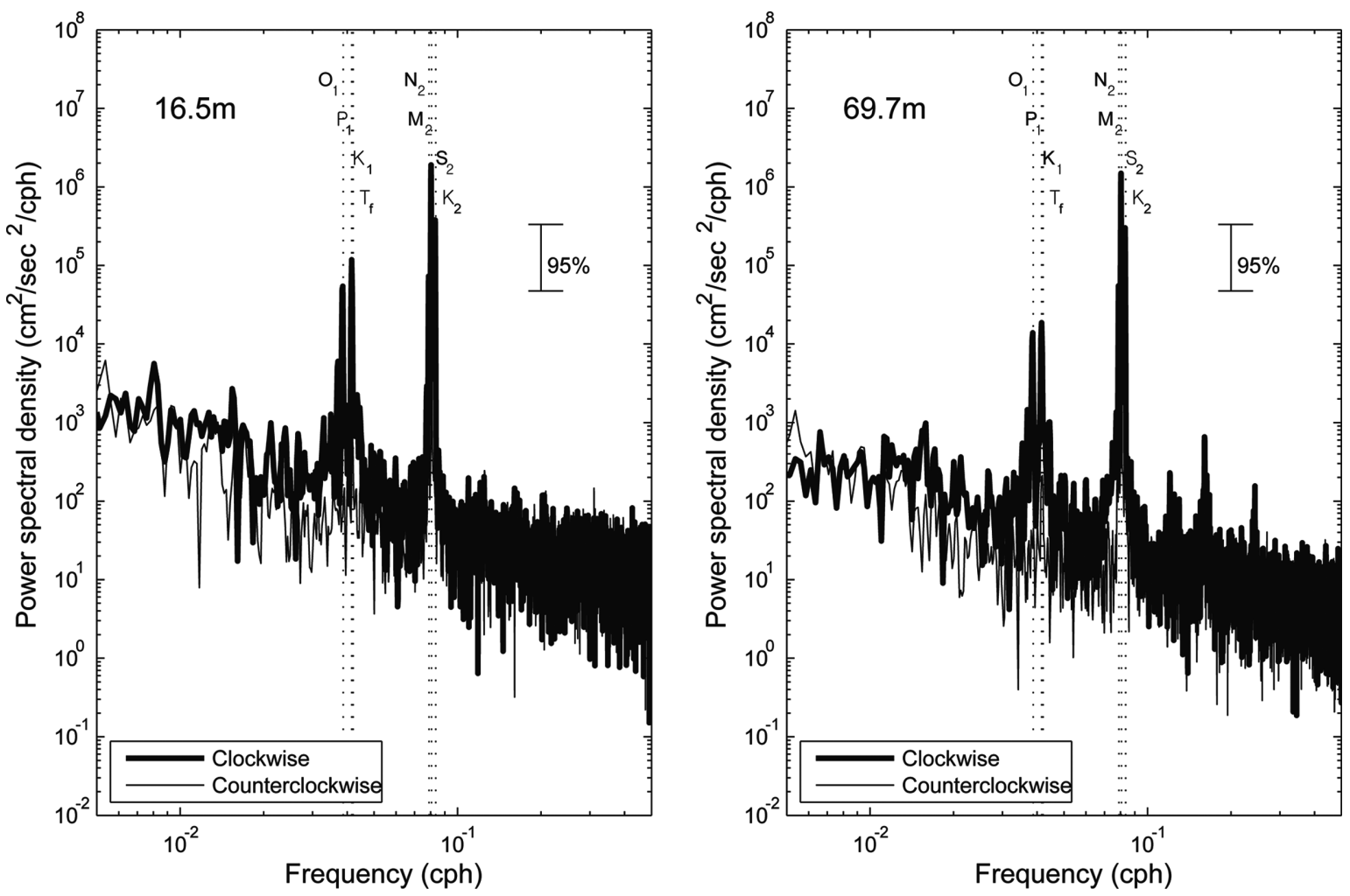

Fig. 5. Rotary spectral densities of kinetic energy at depths $16.5 \mathrm{~m}$ and $69.7 \mathrm{~m}$. Frequencies of major tidal constituents, $O_{1}, P_{1}, K_{1}, N_{2}, M_{2}, S_{2}$ and $K_{2}$, and the inertial oscillation $\left(T_{f}\right)$ are indicated
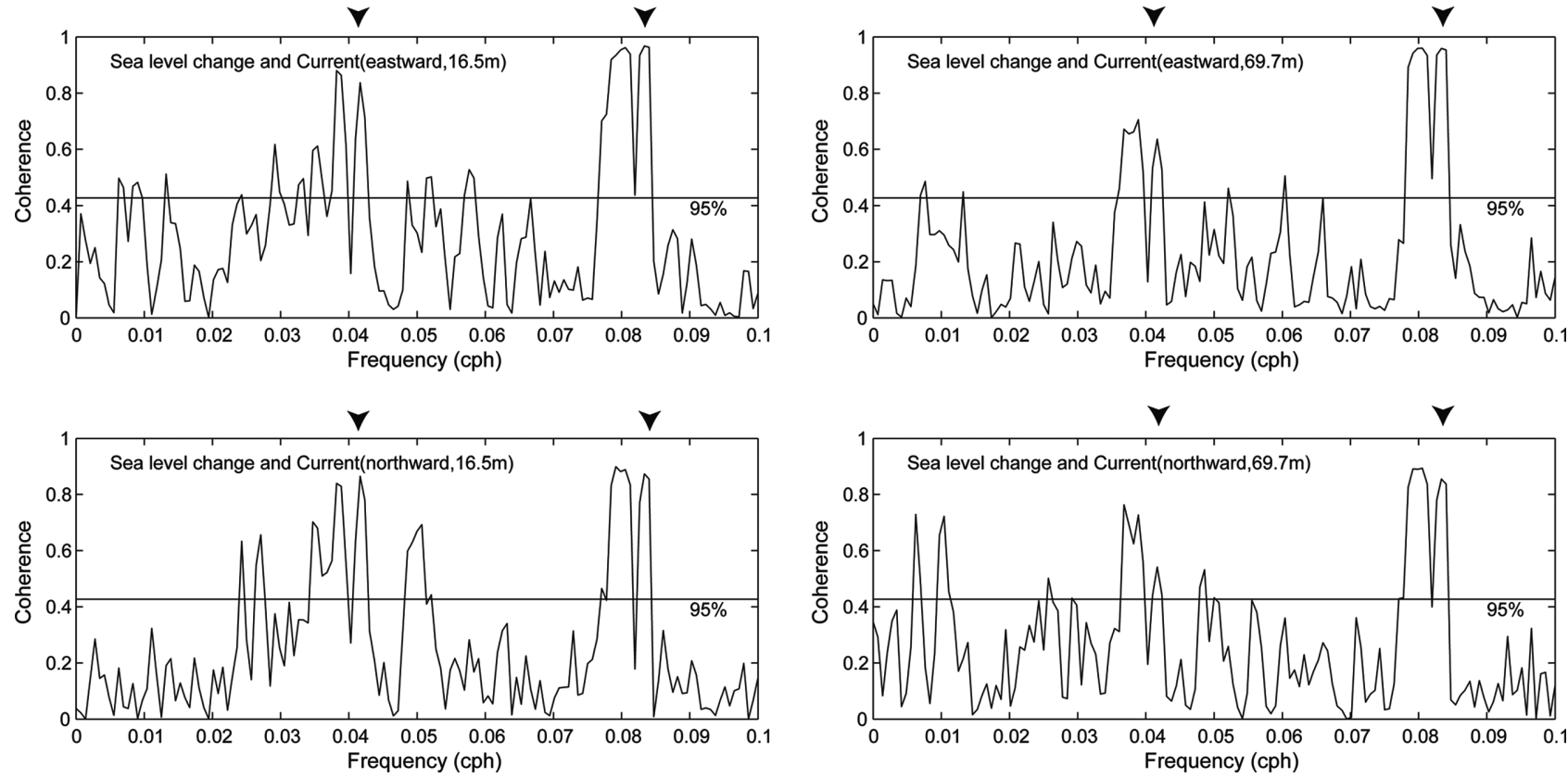

Fig. 6. Coherences between sea level change and either eastward (upper) or northward (lower) component of current at depths $16.5 \mathrm{~m}$ (left) and $69.7 \mathrm{~m}$ (right). Arrows on the upper side indicate the frequencies of 1/12 cph and $1 / 24 \mathrm{cph}$ 

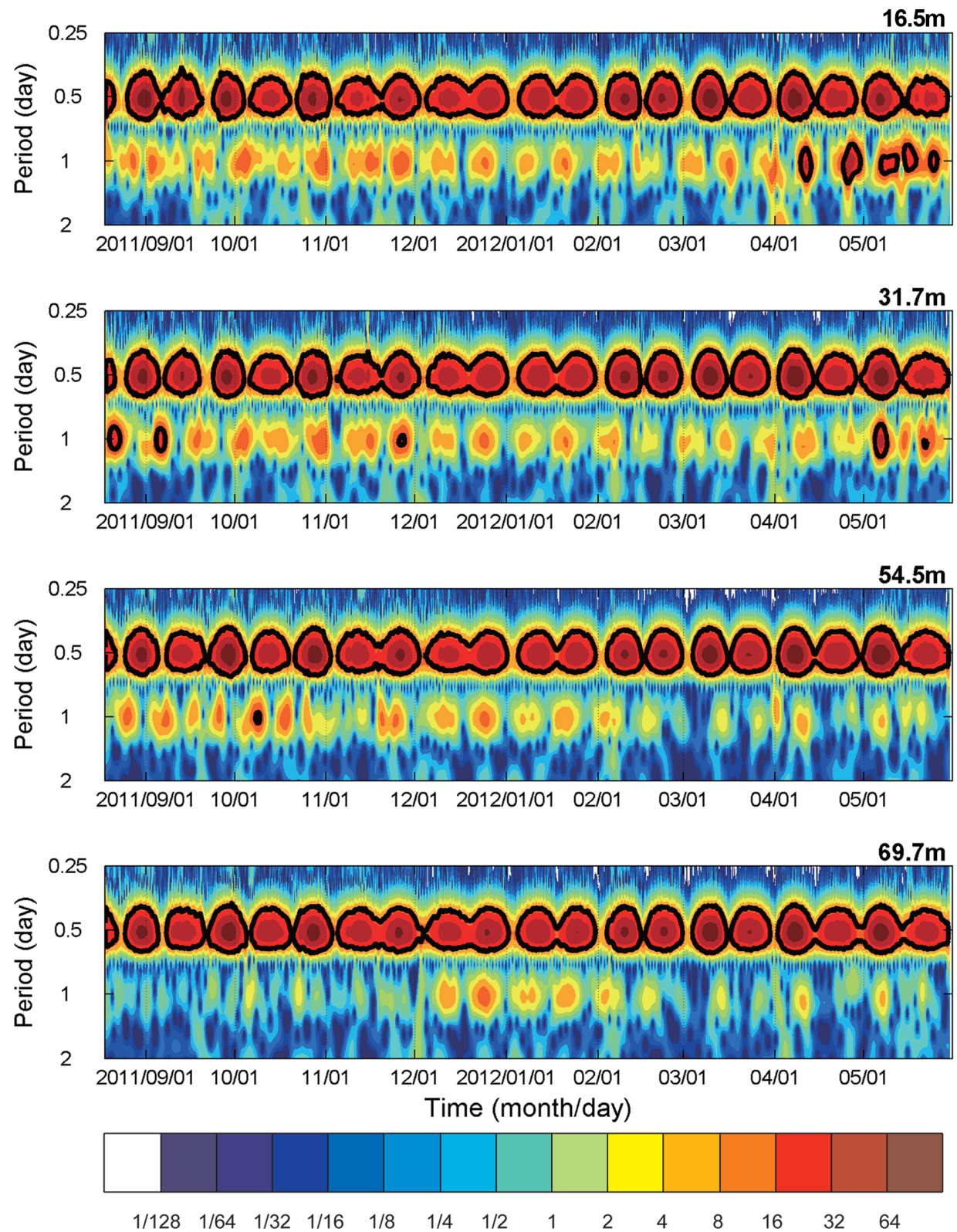

Fig. 7. Wavelet spectra of kinetic energy at four selected depths. Units are in $\mathrm{cm}^{2} / \mathrm{sec}^{2}$

Table 4. Barotropic and baroclinic kinetic energies contained in the "semi-diurnal current" (semi-diurnal), "diurnal current" of tidal origin (diurnal tidal) and inertial oscillation (diurnal inertial) for each of three sub-periods. Units are in $\mathrm{cm}^{2} / \mathrm{sec}^{2}$

\begin{tabular}{ccccc}
\hline \multirow{2}{*}{ Period } & Surrent & Semi-diurnal & Diurnal \\
\cline { 4 - 5 } $2011.8 \sim 2011.9$ & Barotropic & $4.72 \mathrm{E}+02$ & $1.71 \mathrm{E}+01$ & Inertial \\
& Baroclinic & $3.48 \mathrm{E}+00$ & $3.33 \mathrm{E}+00$ & $1.92 \mathrm{E}+00$ \\
\multirow{2}{*}{$2011.12 \sim 2012.2$} & Barotropic & $4.17 \mathrm{E}+02$ & $2.21 \mathrm{E}+01$ & $6.91 \mathrm{E}+00$ \\
& Baroclinic & $3.05 \mathrm{E}+00$ & $2.27 \mathrm{E}+00$ & $1.05 \mathrm{E}+00$ \\
$2012.4 \sim 2012.5$ & Barotropic & $4.45 \mathrm{E}+02$ & $1.62 \mathrm{E}+01$ & $3.00 \mathrm{E}+00$ \\
& Baroclinic & $3.59 \mathrm{E}+00$ & $4.11 \mathrm{E}+00$ & $4.22 \mathrm{E}+00$ \\
\hline
\end{tabular}



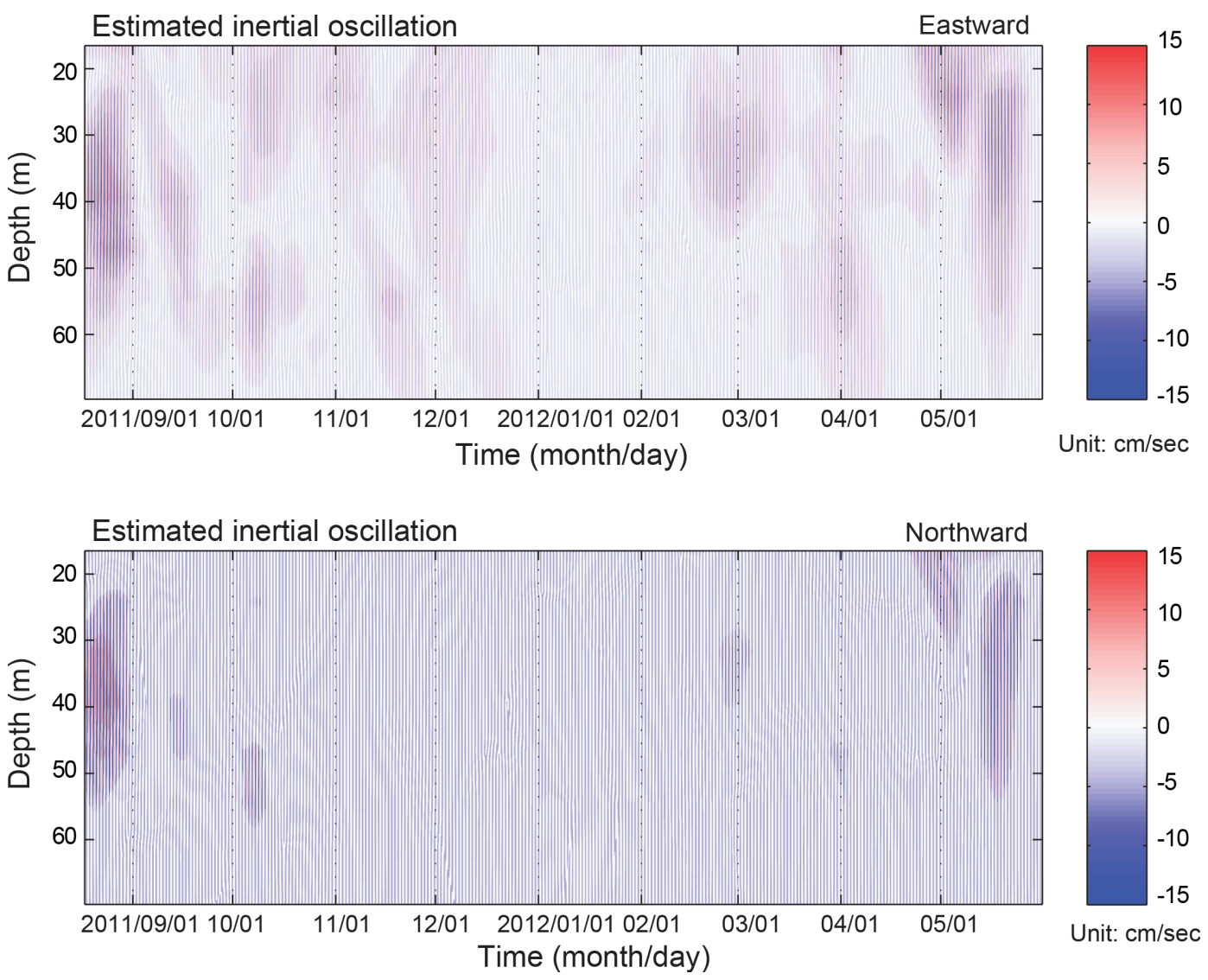

Fig. 8. Time-depth diagram of eastward (upper) and northward (lower) components of current associated with the estimated inertial oscillation contributing to the "diurnal current"

oscillation contributing to the "diurnal current" appears to be more prominent when the current is baroclinic, indicating that stratification plays an important role in generation of inertial oscillations. To check if the inertial oscillation is generated by wind, a time-depth diagram of the estimated inertial oscillation was drawn (Fig. 8). There is no indication of downward energy propagation, implying that the inertial oscillation is not generated by wind. Although not shown here, this fact is further confirmed in the more detailed vertical structure of the current. Presently, it is not known how then the inertial oscillation is generated.

The characteristics of "semi-diurnal" and "diurnal currents" described above can be compared with those observed previously in the "slope-area" by Park et al. (2012). For the "semi-diurnal current", the two areas are quite different. It is predominantly barotropic in the "KOGA-area" even in summer, whereas it is baroclinic in the "slope-area" in summer. It seems that internal tidal waves are generated topographically in the latter area but they are dissipated before arriving at the "KOGA-area" further onshore. The diurnal baroclinic waves are also observed in the "slope- area" in summer and are interpreted as the near-inertial waves generated by wind with downward energy propagation. However, these waves can also be considered as horizontally propagating internal waves with first-mode vertical structure, probably the topographically-generated internal tidal waves. In the "KOGA-area", the "diurnal current" of tidal origin is strongly barotropic in winter. It still remains largely barotropic in spring and summer when the water column is more stratified, although it becomes more baroclinic than in winter. Hence, the "diurnal current" in the "KOGA-area" is also more barotropic than in the "slope-area", probably because of the different topographic effects between them.

\section{Conclusions}

The long-term mooring performed at a KOGA station reveals some characteristics of "semi-diurnal" and "diurnal currents", the former and latter being defined as the mixtures of motions with periods around, respectively, a half day and a day. These currents appear to be predominantly tidal 
and significantly coherent with sea level changes around the semi-diurnal and diurnal frequencies. The time series of "semi-diurnal current" for the whole period of observation was constructed with all the available major semi-diurnal tidal harmonic constituents. In the same way, the "diurnal current" of tidal origin can also be constructed. The time series of inertial oscillation contained in the "diurnal current" was estimated by subtracting the "diurnal current" of tidal origin, obtained above, from the raw data and then by band-pass filtering it. Barotropic and baroclinic kinetic energies were calculated for the "semi-diurnal current", the "diurnal current" of tidal origin and the estimated inertial oscillation, using the vertical averages of the currents and the deviations from them, for three sub-periods, from Aug., 2011 to Sep., 2011 representing summer, from Dec., 2011 to Feb., 2012 representing winter, and from Apr., 2012 to May, 2012 representing spring. The "semi-diurnal current" is strongly barotropic all year round. This fact contrasts strongly with previous observations performed in the "slope-area", about $70 \mathrm{~km}$ nearer to the slope, that reported the "semi-diurnal current" being strongly baroclinic in summer. The "diurnal current" of tidal origin is strongly barotropic in winter. In spring and summer, however, it becomes more baroclinic although it still remains largely barotropic. Hence, the "diurnal current" is also more barotropic in the "KOGA-area" than in the "slope-area". The inertial oscillation contributing to the "diurnal current" appears to be more prominent when the current is baroclinic, indicating the important role played by stratification in generation of inertial oscillations.

There is no clear indication of downward energy propagation in the estimated inertial oscillation, suggesting that inertial oscillation is not created at the surface by wind. The complicated vertical structure of the estimated inertial oscillation may indicate that at least a part of it is associated with vertically high-mode inertial waves (daughter waves) created from the vertically low-mode tidal waves (mother waves), the internal waves of $\mathrm{S}_{2}$ tidal constituent in this case, as predicted by the theory of parametric subharmonic instability (PSI). This is particularly so because the "KOGA-area" is both near the critical latitude where the local inertial period becomes twice that of a major tidal constituent, and near the continental slope where the generation of internal tidal waves is favored. The energy transfer rate from the tide to near-inertial motions through the PSI may be estimated using the method employed by MacKinnon et al. (2013), for which vertical motions should be known. Unfortunately, there is no information about the vertical motion in the "KOGA-area". This information will be obtained in near future when perfectly designed mooring experiments are devised.

\section{Acknowledgements}

This study was supported by Korea Hydrographic and Oceanographic Administration as a part of the project "Analyses of data obtained from Korea Ocean Observing Network (KOON)".

\section{References}

Baines PG (1982) On internal tide generation models. DeepSea Res 29(3):307-338

Choi BH (1980) A tidal model of the Yellow Sea and the Eastern China Sea. KORDI, Ansan, 72 p

Emery WJ, Thomson RE (1997) Data analysis methods in physical oceanography. Elsevier, Amsterdam, 638 p

Ichikawa H, Beardsley R (2002) The Current System in the Yellow and East China Seas. J Oceanogr 58(1):77-92

Isobe A (2008) Recent advances in ocean-circulation research on the Yellow Sea and East China Sea shelves. J Oceanogr 64(4):569-584

KHOA (2012) Reports of the project, Analyses of data obtained from Korea Ocean Observing Network (KOON). 271 p (in Korean)

KHOA (2013) IEODO Ocean Research Station http:// ieodo.khoa.go.kr Accesed 4 Mar 2014

Kuroda Y, Mitsudera H (1995) Observation of internal tides in the East China Sea with an underwater sliding vehicle. J Geophys Res-Oceans 100(C6):10801-10816

Larsen LH, Cannon GA, Choi BH (1985) East China Sea tide currents. Cont Shelf Res 4(1-2):77-103

Lie HJ, Cho CH (1994) On the origin of the Tsushima Warm Current. J Geophys Res-Oceans 99(C12):2508125091

Lie HJ, Cho CH, Lee JH, Lee S, Tang Y, Zou E (2001) Does the Yellow Sea Warm Current really exist as a persistent mean flow? J Geophys Res-Oceans 106(C10): 22199-22210

MacKinnon JA, Alford MH, Sun O, Pinkel R, Zhao Z, Klymak J (2013) Parametric Subharmonic Instability of the Internal Tide at $29^{\circ} \mathrm{N}$. J Phys Oceanogr 43(1):17-28

Niwa Y, Hibiya T (2004) Three-dimensional numerical simulation of $\mathrm{M}_{2}$ internal tides in the East China Sea. J Geophys Res-Oceans 109(C4):C04027

Park JH, Lie HJ, Guo B (2011) Observation of Semi-diurnal Internal Tides and Near-inertial Waves at the Shelf Break of the East China Sea. Ocean and Polar Res 33(4):409- 
419

Pawlowicz R, Beardsley B, Lentz S (2002) Classical tidal harmonic analysis including error estimates in MATLAB using T_TIDE. Comput Geosci 28(8):929-937

$\mathrm{Su}$ J (1998) Circulation dynamics of the China Seas north of $18^{\circ}$ N. J Korean Soc Oceanogr 11:483-505

Takahashi D, Morimoto A (2013) Mean field and annual variation of surface flow in the East China Sea as revealed by combining satellite altimeter and drifter data. Prog Oceanogr 111:125-139
Torrence C, Compo GP (1998) A Practical Guide to Wavelet Analysis. B Am Meteorol Soc 79(1):61-78

Yanagi T, Morimoto A, Ichikawa K (1997) Co-tidal and corange charts for the East China Sea and the Yellow Sea derived from satellite altimetric data. J Oceanogr 53(3): 303-310

Received Oct. 21, 2013

Revised Jan. 6, 2014

Accepted Feb. 11, 2014 